\title{
FEATURE \\ The National Institute of Food and Agriculture: Addressing the agricultural impacts of and vulnerabilities to climate change
}

\author{
Michael Bowers, Nancy Cavallaro, and Sonny Ramaswamy
}

$\mathrm{T}$ here can be no doubt that agricultural, forestry, and range production systems and natural systems are dramatically affected by climate variability and change. Producers, land managers, and other decision makers need information, technologies, and decision-support tools about greenhouse gas (GHG) mitigation, adaptation strategies, and policy outcomes. Crop, animal, forest, range, and even urban and rural management approaches must take climate variability into account to implement adaptation strategies and improve sustainability over the long term. The potential for forests and agricultural lands to serve as carbon (C) sinks and to reduce GHG emissions must be quantified to support sound policies and environmental markets. Outreach and extension networks must be implemented to employ climate change mitigation and adaptation strategies in management practices and to use scientific findings for restoration projects, planning, interventions, and prescriptions.

The 2008 Farm Bill passed by the United States Congress called for the establishment of the USDA's National Institute of Food and Agriculture (NIFA). As a replacement for the former Cooperative State Research, Education, and Extension Service, NIFA had a new mandate to serve as USDA's extramural science agency. Under its flagship competitive grants program, the Agriculture and Food Research Initiative (AFRI), NIFA identified a set of grand societal challenges to be addressed and created a portfolio of challenge areas including food security, water, climate change, sustainable bioenergy, childhood obesity and nutrition, and food safety. This portfolio also included funding for the discovery of foundational knowledge, as well as the establishment of a pipeline for new scientists under its Fellowships Program.

Michael Bowers and Nancy Cavallaro are national program leaders, and Sonny Ramaswamy is director of the USDA National Institute of Food and Agriculture, Washington, DC.
The 2008 Farm Bill and the recently passed 2014 Farm Bill provide additional competitive grants under several mandatory programs, including the Specialty Crops Research Initiative, the Organic Research and Extension Initiative, the Beginning Ranchers and Farmers Development Initiative, and the Biomass Research and Development Initiative. Along with these and other smaller competitive grants programs, NIFA also provides funding to support research, extension, and education capacity through Hatch, Smith-Lever, McIntire-Stennis, Evans-Allen, and other such legislative funding authorities available for the vast system of land-grant universities in the United States.

NIFA's science funding portfolio contributes significantly to USDA's mission to provide leadership on food, agriculture, natural resources, rural development, nutrition, and related issues based on sound public policy, the best available science, and efficient management. NIFA is unique among many federal departments due to its broad mission, which includes research, education, technology transfer, public land management, and technical assistance to private landowners to name a few. NIFA's responsibilities center on people and land, both private and public; rural and urban communities; fish and wildlife habitats; forest lands; croplands; grasslands; wetlands; agro-forest ecosystems; and agricultural and forest products. NIFA's most significant difference from other science agencies is its emphasis on user-inspired science and participatory approach, which uses formal and informal interactions with farmers, ranchers, forest landowners, scientists, researchers, extension personnel, and other stakeholders to develop its science and funding priority decisions. The Cooperative Extension System in the United States has developed trusted partnerships in its 100-year history through science-based decision support, programmatic assistance, extramural education, technical guidelines, and methods for natural resource management.
To address climate change impacts and vulnerabilities in the agricultural domain, NIFA's Agricultural Science for Climate Variability and Change Programs include the following efforts:

- Forecasting climatic stress at relevant scales. One of the most commonly occurring challenges is the inability to forecast changes in climate, climate variability, extreme events, and weather on scales that can provide meaningful knowledge and information to USDA and its stakeholders. Current projections of climatic changes are important to understand and to be able to anticipate the causes and impacts of a changing climate at regional and national scales. For the local needs of individual landowners, impacts are exceedingly difficult to predict.

- Employing tools to identify and predict climate change impacts at appropriate temporal and spatial scales. It is difficult to definitively decouple the impacts that can be attributed to climate change from other factors that traditionally impact agronomic operations.

- Forecasting how and where climate change is most likely to influence risk pathways for pests, notably agricultural diseases; forest, crop, and livestock pests; and food-borne pathogens that could potentially affect global food and agricultural systems.

- Addressing uncertainties in methodologies (empirical and process-based) used to evaluate any changes in climate with specific resource impacts and the feedbacks of interventions and actions for adaptation and mitigation to the climate system and the environment.

- Increasing knowledge of climate dynamics and uncertainties for policy and strategic planning. Climate dynamics are extremely complex, and predicted shifts in climate conditions are associated with a great deal of uncertainty, particularly with respect to changes in precipitation patterns, in the variability of weather patterns, and in the frequency of extreme events. Such 
uncertainty presents a challenge to the ability to generate policy-relevant research results that can help inform distribution of resources, targeted policy and program recommendations, and design of adaptation strategies. An additional challenge is supporting analytics for adaptive strategic planning that systematically considers regional and sectoral influences.

- Developing useable information and effective communication. Public perceptions of climate change discussions can create resistance to the importance of climate change education. Information needs to be presented in a manner that stakeholders can identify and accept more easily. Impacts of climate variability, addressed in an economic, social, and environmental context, can illustrate the impacts of societal challenges and, thus, be accepted more readily.

The US Global Change Research Program's National Climate Assessment of 2014 observes that key vulnerabilities to climate change in the United States include temperature increases across the country with the most notable increases expected to occur during coldest winter months over interior and northern Alaska and across the northern tier of interior, continental states; less rapid warming of coastal regions than inland regions of the continental United States; more frequent heat waves across North America; and more intense precipitation, which may produce more frequent flood-producing storms. In light of these predicted impacts and vulnerabilities, the report calls on federal and state agencies and governments to be prepared to accommodate these shifts in climate.

Major climate drivers associated with human health can be both direct and indirect and include increasingly frequent and intense weather events. For instance, extreme heat conditions and longer growing seasons intensify drought, wildfires, and associated air pollution. Also, changing precipitation patterns and increasingly intense storms and sea level rise can lead to many health-related issues via storm surges and increased flooding with accompanying loss of life and property, injury, impaired water quality, and vulnerability to disease.

Agricultural production changes due to climate variability and change can lead to volatility in food surplus and deficits in regions where food insecurity is common or potentially difficult to manage due to transportation disruptions. Food assistance programs experience increases in the number of requests for market assistance under severe weather conditions, such as flooding, hurricanes, and tornadoes.

The diverse ecosystems within forests and grasslands are fundamental to the multiple socioeconomic benefits these land types provide. Climate change affects those ecosystem services, for example, by changing forest and rangeland productivity, which in turn influences biomass availability for livestock and wildlife grazing, wood products, and energy. The increased occurrence of severe droughts or other extreme events can alter the long-term ecosystem composition, structure, and function as plant and animal species respond to climate change.

Loss of ecosystem services from open and marginal spaces is also a concern. National forests, grasslands, surrounding farms, ranches, and private timber lands protect water quality; provide wildlife habitat, wood, and other products; and offer places for recreational purposes. Open spaces, and the ecological and socioeconomic benefits they provide, are lost when forests and working lands are converted to urban and industrial uses. Climate change could lead to declines in productivity of agricultural land or conversion of productive farmlands, forest, and rangelands to accommodate residential housing or recreational needs.

Increased impacts from catastrophic wildfire and attempts to restore fire to appropriate landscape locations are additional threats from climate change. Recent trends indicate increased fire occurrence and severity will impact annual acreages burned, particularly in the western United States. In addition, fires encompassing extremely large geographic areas are less responsive to suppression control efforts.

Other potential human and public health impacts of climate change include increased risk of respiratory stress from poor air qual- ity; potentially increased occurrence of allergens contributing to respiratory illnesses and asthma; heat exhaustion of workers in agricultural tasks and other endeavors; and impacts on mental health such as increased anxiety and post-traumatic stress, especially in vulnerable populations and areas of increasing food insecurity and/or crop failures and livestock losses. Food safety issues are likely to rise due to increased occurrence and severity of microbial contamination, challenges of food preservation, and transportation.

As part of NIFA's strategy to address different sectors of the climate change portfolio, a set of applied climate tracks was developed that identified major areas of application of research, education, and extension activities. Each track has identified a set of achievable outcomes during the next 10 years that were used to populate the outcomes of logic models as part of a roadmap for NIFA's climate change portfolio (table 1).

Mechanisms for adapting to and mitigating climate change are critical for continued agricultural production and stewardship of natural resources. New research, education, and extension activities are necessary to increase the resilience of agronomic systems to climate change and to benefit from new opportunities that may arise. 


\section{Table 1}

A set of applied climate tracks and outcomes developed by the USDA National Institute of Food and Agriculture to identify major areas of application of research, education, and extension activities.

\begin{tabular}{ll}
\hline Track & Outcomes \\
\hline $\begin{array}{l}\text { Agroecosystem } \\
\text { production and } \\
\text { resource management }\end{array}$ & Reduce energy, nitrogen (N), carbon (C), and water footprints in agricultural production systems. \\
Increase management options for producers that sequester soil C. & Develop and implement new N fertilizer recommendations that optimize yield while reducing greenhouse gas (GHG) emissions. \\
& Measure fluxes of GHG from agriculture sources to the atmosphere. \\
& Develop new methods for GHG flux measurements. \\
& Develop process-based models for GHG generation. \\
& Improve agricultural and forest sector inputs to climate change models. \\
& Improve GHG inventories. \\
& Mitigate negative impacts of arthropods, diseases, and invasive species outbreaks on crop, livestock, and forest productivity. \\
& Identify new production practices that increase soil C while reducing GHG emissions. \\
& Develop appropriate adaptation strategies to increase resilience of agricultural and forestry production systems. \\
\hline Genomics and breeding & Translate genomics research and resulting technologies to the agricultural and forestry production sector to adapt to \\
& and mitigate impacts of climate change. \\
& Develop varieties of crop plants and breeds of animals that maximize C sequestration and can adapt to current and \\
& future climate conditions. \\
& Develop transgenic approaches for enhanced adaptation to biotic and abiotic stress in many different environments. \\
Characterize United States germplasm collections to identify useful genetic variation for molecular breeding. \\
Increase knowledge of water use efficiency, N use efficiency, nutrient utilization, and C sequestration. \\
Develop or improve high-throughput phenotyping and genotyping to improve accuracy of genetic selection. \\
Develop coordinated solutions to data access, data analysis, and data synthesis for breeders. \\
Develop toolkits to enable systems-level analysis to allow targeted and predictable breeding strategies. \\
Enhance international research coordination and cooperation in translational genomics, genetics, and breeding for climate change.
\end{tabular}

economic dimensions
Human and

Assess USDA nutrition recommendations to ensure nutritional adequacy and mitigate impacts of climate change on humans.

Promote innovations in food supply chain linkages (knowledge, distribution, and business practices) that reduce GHG emissions and successfully convey that attribute to end users.

Identify and help remove local, regional, or national barriers that exist (i.e. structural, market, policy) to adoption of on-farm technologies and/or practices that can reduce $\mathrm{C}, \mathrm{N}$, and water footprints.

Identify and promote strategies that successfully influence consumer food purchase decisions to include the value of climate impacts. Facilitate producer decision-making to incorporate awareness of climate impacts on production systems, labor, markets, and trade. Identify incentives (legislation, administration, financing) for improving soil C management.

Promote greater understanding of the importance of changing demographics and social networks as drivers affecting soil

C management.

Assess impacts of alternative mitigation and/or adaptation strategies on prosperity of rural communities.

Formal and

nonformal education Increase the number of agricultural scientists who have cross-disciplinary training in climate change science. Increase supply of graduates to meet the climate change workforce.

Supply faculty to meet climate change teaching and research demands.

Enhance education, training, and outreach to undergraduate and graduate students and postdoctoral researchers to enable cross-disciplinary training in climate change science and create new biology job opportunities for investigators at all levels. Enhance knowledge of climate change and its impacts in 4-H program participants.

Extension and outreach Increase awareness and knowledge in the public by providing evidence-based critical climate change information. Promote adoption of practices that sequester $\mathrm{C}$ in agriculture and forest ecosystems.

Promote adaptive management alternatives to reduce vulnerability to changing climate.

Develop appropriate outreach materials about climate smart practices and provide them to landowners, businesses, agencies, and other members of the public.

Raise awareness in youth and adults regarding C, N, energy, and water footprint of food, fiber, and fuel production. Broaden societal impacts by engaging public-private partnerships with industry, grower associations, and private foundations. Develop age-appropriate educational and outreach materials about climate change for youth audiences.

Help develop and provide decision support tools to decision makers. 